LA-UR-97- 98

Title:

Carbon Stripper Foils Used in the Los Alamos PSR

CONF-970503--

Author(s):

M. Borden

M. A. Plum

I. Sugai

RECEIVED

DEC 161997

OSTI

Submitted to:

'97 Particle Accelerator Conference

DISTRIBUTION OF THIS DOCUMENT IS URH MITED
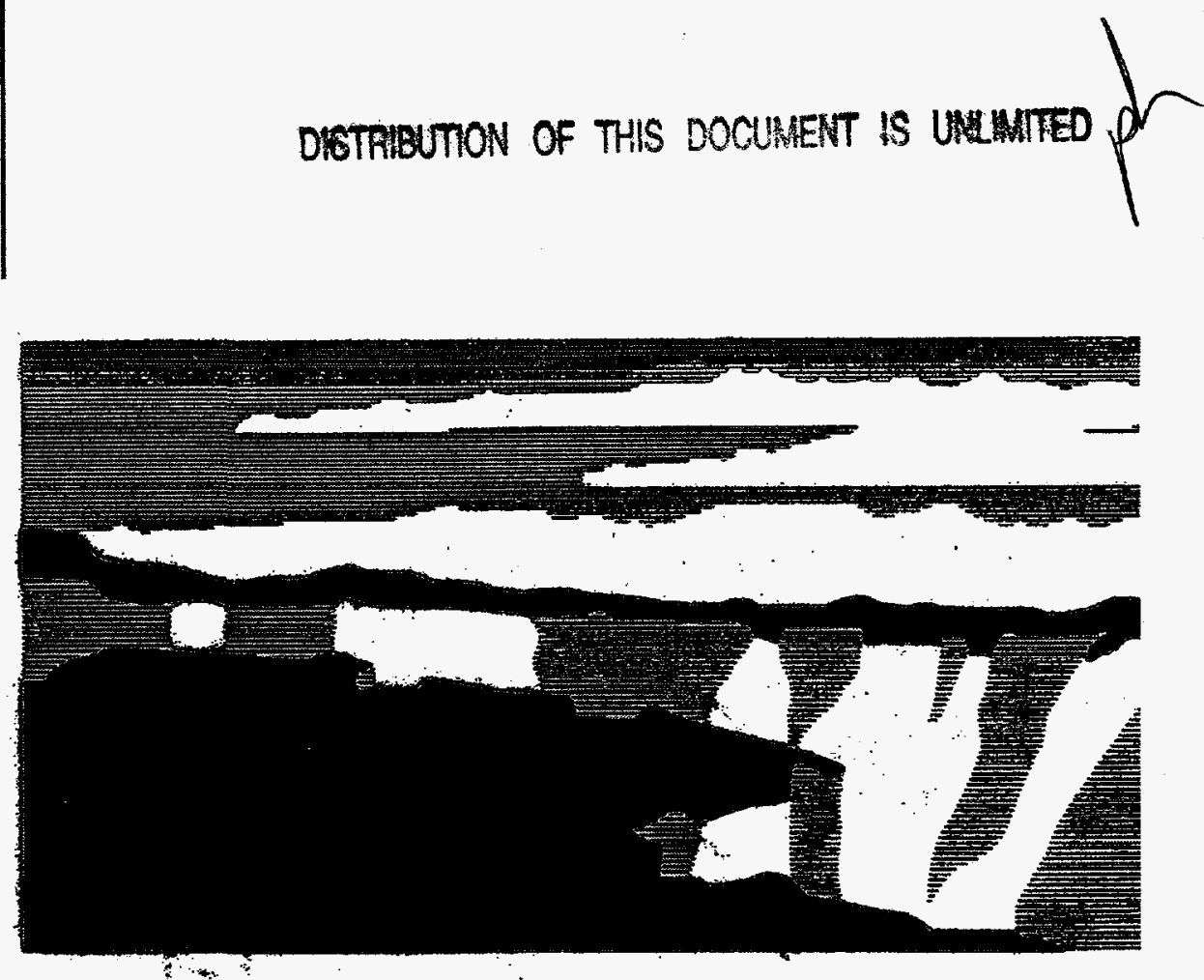

Los Alamos National Laboratory, an affirmative action/equal opportunity employer, is operated by the University of Califomia for the U.S. Department of Energy under contract W-7405-ENG-36. By acceptance of this article, the publisher recognizes that the U.S. Government retains a nonexclusive, royalty-free license to publish or reproduce the published form of this contribution, or to allow others to do so, for U.S. Government purposes. The Los Alamos National Laboratory requests that the publisher identify this article as work performed under the auspices of the U.S. Department of Energy. 


\section{DISCLAIMER}

This report was prepared as an account of work sponsored by an agency of the United States Government. Neither the United States Government nor any agency thereof, nor any of their employees, makes any warranty, express or implied, or assumes any legal liability or responsibility for the accuracy, completeness, or usefulness of any information, apparatus, product, or process disclosed, or represents that its use would not infringe privately owned rights. Reference herein to any specific commercial product, process, or service by trade name, trademark, manufacturer, or otherwise does not necessarily constitute or imply its endorsement, recommendation, or favoring by the United States Government or any agency thereof. The views and opinions of authors expressed herein do not necessarily state or reflect those of the United States Government or any agency thereof. 


\section{DISCLAMIER}

Portions of this docament may be illegible in electronic imoge products. Images are produced from the best available original document 


\title{
Carbon Stripper Foils Used in the Los Alamos PSR
}

\author{
M. J. Borden, M. A. Plum, MS H838, Los Alamos National Laboratory, Los Alamos, N.M., 87545, \\ U.S.A.; I. Sugai, INS, University of Tokyo, Midori-cho, Tanashi-shi, Tokyo 188, Japan
}

Abstract

Carbon stripper foils produced by the modified controlled ACDC arc discharge method (mCADAD) at the Institute for Nuclear Study have been tested and used for high current $800-\mathrm{MeV}$ beam production in the Proton Storage Ring (PSR) since 1993. Two foils approximately $110 \mu \mathrm{g} / \mathrm{cm}^{2}$ each are sandwiched together to produce an equivalent $220 \mu \mathrm{g} / \mathrm{cm}^{2}$ foil. The foil sandwich is supported by $4-5 \mu \mathrm{m}$ diameter carbon fibers attached to an aluminum frame. These foils have survived as long as five months during PSR normal beam production of near $70 \mu \mathrm{A}$ average current on target. Typical life-times of other foils vary from seven to fourteen days with lower on-target average current. Beam loss data also indicate that these foils have slower shrinkage rates than standard foils. Equipment has been assembled and used to produce foils by the mCADAD method at Los Alamos. These foils will be tested during 1997 operation.

\section{CARBON FOIL REQUIREMENTS}

The LANL Proton Storage Ring (PSR) currently uses a two-stage stripping process. $\mathrm{H}-$ ions are first neutralized with a high field electro-magnet, injected into the PSR through the first ring dipole, and then stripped to $\mathrm{H}^{+}$(protons) with a carbon stripper foil. The LANSCE Reliability Improvement Project (LRIP), which is now underway, will remove the high field electro-magnet and allow single-stage stripping [1].

Beam losses in PSR have two primary causes. Firstturn losses are caused by excited states of $\mathrm{H}^{\circ}$ produced in the injection stripper foil. These particles are lost in the first dipole and quad following the stripper foil and account for loss of about $0.20 \%$. of the injected beam. Production of excited states of $\mathrm{H}^{\circ}$ and, therefore, firstturn losses, decrease as the foil thickness is increased. The second mechanism accounts for most of the losses (about $0.25 \%$ of injected beam) and occurs because of nuclear and large-angle coulomb scattering of the stored circulating beam in the stripper foil. These losses are distributed around the entire ring.

\subsection{Foil requirements prior to the LRIP}

Currently the PSR delivers an average proton beam current of $70 \mu \mathrm{A}$. Original PSR beam-dump design requirements called for stripper foils $90 \%$ efficient. For $800 \mathrm{MeV}$ hydrogen atoms a $200 \mu \mathrm{g} / \mathrm{cm}^{2}$ carbon foil is required. Over the past 10 years of operation we have used carbon foils with a range of mass density from
$185 \mu \mathrm{g} / \mathrm{cm}^{2}$ to $220 \mu \mathrm{g} / \mathrm{cm}^{2}$. A $220 \mu \mathrm{g} / \mathrm{cm}^{2}$ foil is now preferred because first turn losses are reduced.

The PSR foils are currently $16 \mathrm{~mm}$ wide and approximately $55 \mathrm{~mm}$ long. The size of the foil is chosen to minimize scattering losses from interaction with the primary circulating beam and maximize foil lifetime. The foils are slightly larger than the injected beam size of approximately $12 \mathrm{~mm}$. This allows for foil shrinkage and hence a longer lifetime. The foil assembly is made up of two foils of nominal thickness $110 \mu \mathrm{g} / \mathrm{cm}^{2}$, sandwiched together between glass slides and cut to size with a laser. The laser cut edges partially bond and assist in holding the two foils together. Two aluminum frames are strung with 4-5 $\mu \mathrm{m}$ diameter carbon fibers orthogonally and diagonally. The doubled foil is then glued along one edge to an aluminum frame with a conductive paint. The two aluminum frames are bolted together with the doubled foil suspended between the carbon fiber grids. See Reference 2 and Fig. 1.

\subsection{Foil Requirements for LRIP}

When LRIP is completed, direct $\mathrm{H}^{-}$injection and phase space painting (beam bumping) should reduce overall beam losses by a factor of five. The circulating beam will be moved off of the stripper foil during the injection period and the injected beam will be better matched to the circulating beam. These techniques allow use of a smaller width foil with a higher mass density. This will reduce the circulating beam interaction with the stripper foil and decrease the production of $\mathrm{H}^{\circ}$ excited states. A more detailed explanation of ring losses may be found in Reference 2. Calculations have shown that a stripper foil with mass density $400 \mu \mathrm{g} / \mathrm{cm}^{2}$ minimizes the sum of the two types of beam loss [3]. The desired average beam current at the completion of the current upgrade is $100 \mu \mathrm{A}$. The stripper foils will be mounted in the fashion described above with the exception that the foil holder will be larger to match the new aperture requirements both upstream and downstream of the stripper foil mechanism.

\section{TESTING CARBON FOILS IN PSR}

Over the past ten years several types of carbon foils have been used in PSR. Foils produced by electron beam evaporation, glow discharge and arc discharge methods have been used. A very detailed lifetime comparison has been made by Sugai, et al. [8]. For comparison Figures 2-3 show the fraction of injected beam lost due to first turn losses for several foils. Note that the first turn losses 
decrease rapidly for the commercial foil as the foil curls, shrinks and becomes thicker. However, first turn losses remain nearly flat for $\mathrm{mCACAD}$ foils throughout the months that these foils were used, attesting to the superior dimensional stability of this type of foil. A mCADAD foil is now in use which has nearly 6 months of beam interaction. This is an order of magnitude longer than other commercially available foils. Most recently we have been using foils produced at the Institute for Nuclear Study, University of Tokyo.
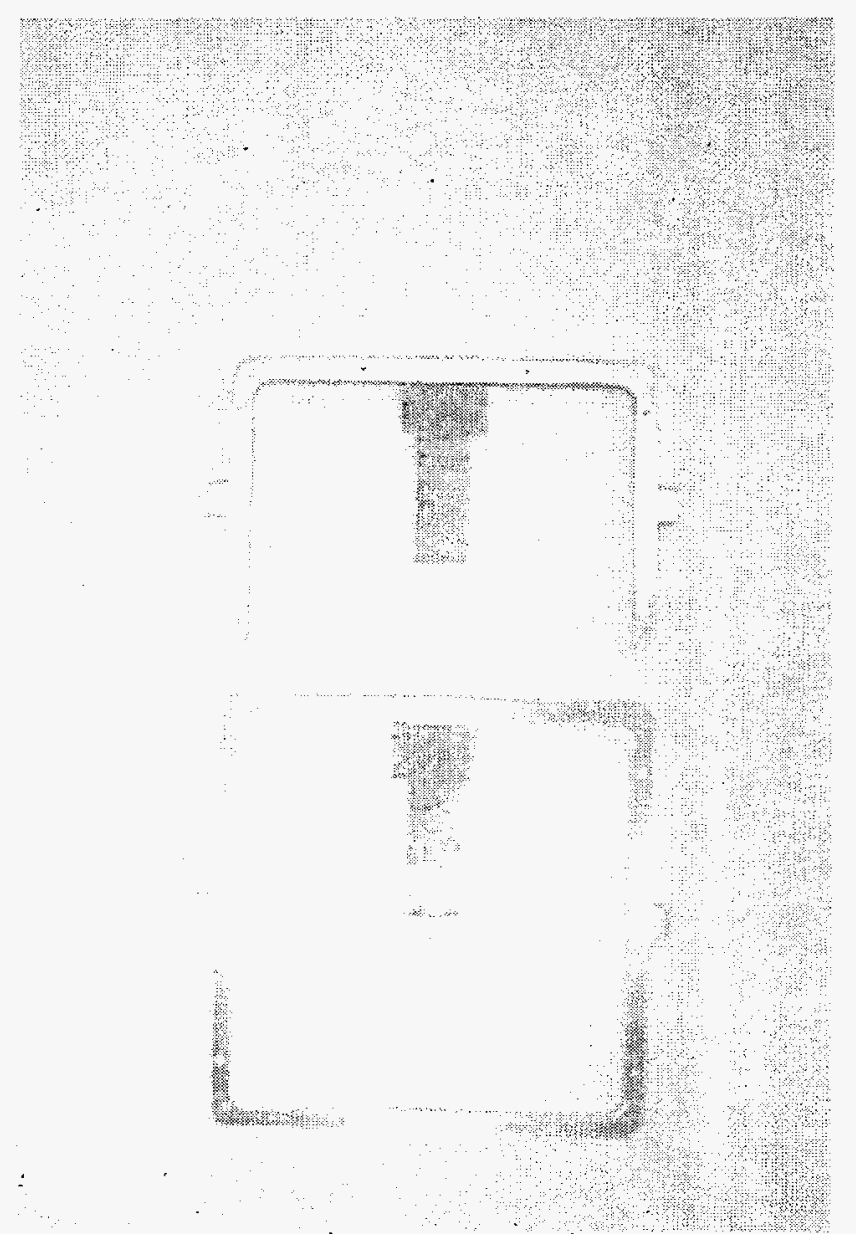

Fig. 1. Aluminum frames with carbon foil and fibers.

\subsection{Carbon foils produced at INS}

The team at the University of Tokyo has developed a technique for producing carbon foils which have shown lifetimes in excess of an order of magnitude higher than commercially available foils. The foils are produced through an arc evaporation process referred to as modified controlled AC/DC arc discharge method (mCADAD) and is described in detail in references [4-8].

The mCADAD foils are produced by arc evaporating alternating layers of carbon produced with $A C$ and then DC current. The carbon is deposited on clean glass substrates and then annealed to remove residual stresses. The mCADAD technique is only limited in that it is not possible to produce foils with a mass density greater than approximately $130 \mu \mathrm{g} / \mathrm{cm}^{2}$ [8]. Work is currently in progress to improve on this limit. With this limitation a minimum of three foils will be necessary to achieve an equivalent thickness of $400 \mu \mathrm{g} / \mathrm{cm}^{2}$ for the upgraded PSR.

\subsection{Foil Production Capabilities at LANL}

An evaporation system has been assembled at LANL with Dr. Sugai's assistance which is capable of producing foils with the mCADAD method. The system consists of a large, stainless steel vacuum chamber, cryo-pump, rotating substrate holder, and arc welding, and annealing power supplies, shown in Fig. 4. The electrode holder. and annealing furnace can be seen in Fig. 5 . The carbon electrode holders are machined from Macor ${ }^{\mathrm{TM}}$. Thickness is measured insitu during deposition with an oscillating quartz crystal monitor. Annealing temperatures are measured with type $\mathrm{K}$ thermocouples placed in contact with the substrate glass and copper homogenizer.

Carbon foils have been produced with this system using the mCADAD method, and initial testing of these foils with the PSR should be completed this year.

First turn loss rate 1993



Fig. 2. First turn loss rate 1993.

First Turn Loss Rate 1995

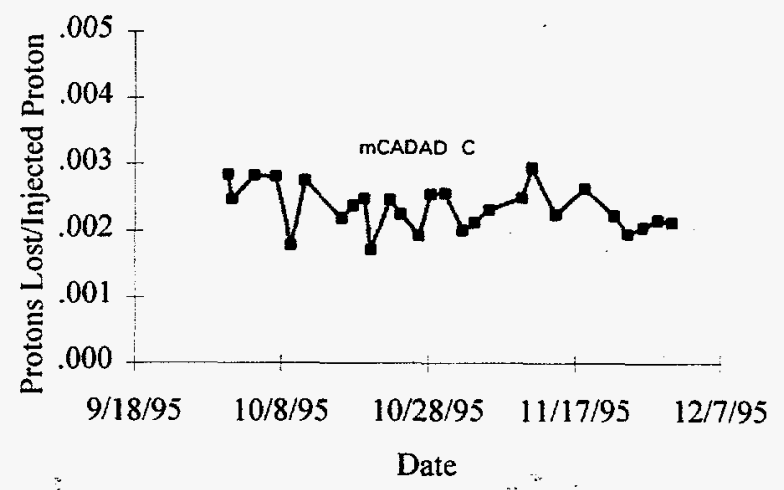

Fig. 3. First turn loss rate 1995. 


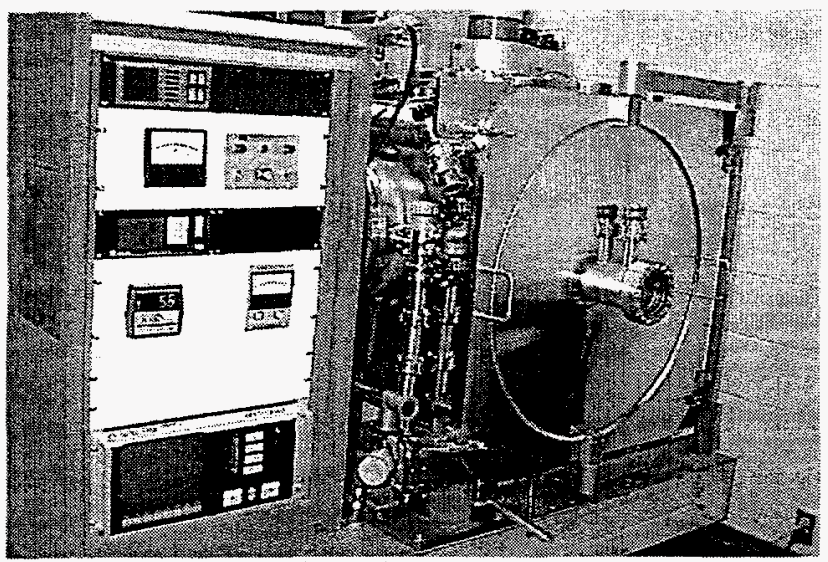

Fig. 4. mCADAD fabrication system.

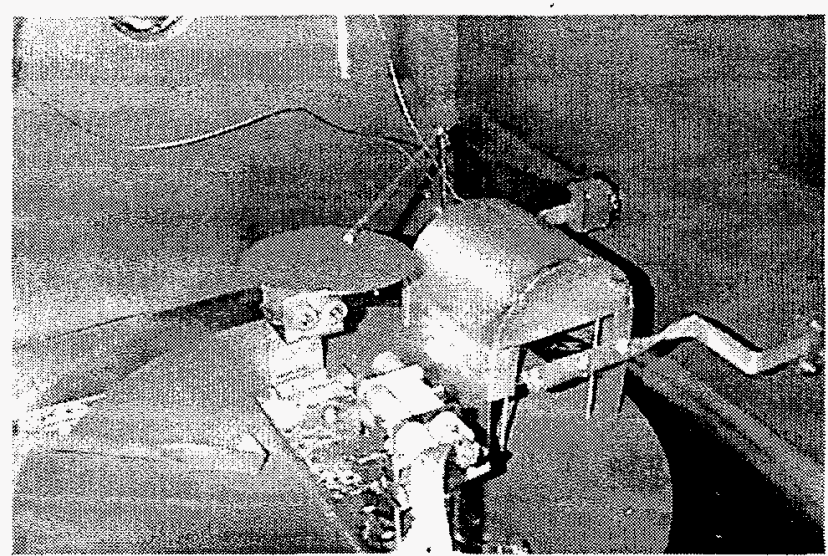

Fig. 5. Electrode holder, center, annealing furnace, right.

\section{CONCLUSIONS}

Carbon foils produced with Dr. Sugai's mCADAD method have significantly improved the operational performance of the Proton Storage Ring. The decreased shrinkage rates associated with these foils allow the use of smaller width foils, thereby decreasing stored beam losses. Lower beam losses imply that the ring components are less radioactivated and therefore worker radiation exposures are reduced. Because of the long lifetimes of these foils, only a few (3-6) are required during the beam operational cycle, further reducing radiation exposures to maintenance personnel. The mechanical stripper foil mechanism can also be of a relatively simple design, even though the LANSCE operations will be extended to eight months per year.

\section{REFERENCES}

[1] D. H. Fitzgerald, et al. 'Overview and Status of the Los Alamos PSR Injection Upgrade Project', these proceedings.

[2] M.J. Borden, G.E. Adamson, R.N. Johnson and W.F. Nicaise, Nucl. Instr. and Meth. A 303 (1991) 63.
[3] "Proton Storage Ring Upgrade to Direct H- Injection: Phase II Technical Design Report" Arch Thiessen, editor, Los Alamos, 7/26/96.

[4] I. Sugai, T. Fujino, K. Yamazaki, T. Hattori and M. Ogawa, Nucl. Instr. and Meth. A236 (1985) 576.

[5] I. Sugai, T. Hattori, H Suzuki, H Kinoshita, H. Kator and K. Yamazaki, Nucl. Instr. and Meth. A 265 (1988) 376.

[6] I. Sugai, T. Hattori, H. Muto, Y. Takahashi, H. Kato, and K. Yamazaki, Nucle. Instr. and Meth. A 282 (1989) 164.

[7] I. Sugai, M, Oyaizu, T. Hattori, K. Kawasaki, T. Yano, H. Muto, Y. Takahashi, and K. Yamzaki, Mucl. Instr. and Meth. A 303 (1991) 59.

[8] I. Sugai, M. Oyaizu, H. Kawakami, C. Ohmori, T. Hatorri, K. Kawasaki, M. J. Borden, R. J. Macek, Nucl. Inst. and Meth. A 362 (1995) 70. 